\title{
DEVELOPMENT OF GEOSPATIAL MAP BASED ELECTION PORTAL
}

\author{
Amit Kumar Chandra Gupta ${ }^{\mathrm{a}}$, Pawan Kumar ${ }^{\mathrm{b}}$, Dr. N. Vasanth Kumar ${ }^{\mathrm{c}}$ \\ ${ }^{a}$ Geospatial Executive - amitkc.gis@ gmail.com, ${ }^{\mathrm{b}}$ Software Developer - pawankr82@gmail.com, \\ ${ }^{\mathrm{c}}$ Managing Director (IAS) - drvasanthias@gmail.com
}

Geospatial Delhi limited, Department of Information Technology, Ministry of Communications and Information Technology

KEY WORDS: Geospatial Map based Election portal (GMEP), Spatial Decision Support System (SDSS), Precinct Area Boundary, Virtual Private Network (VPN), Special Purpose Vehicle (SPV)

\begin{abstract}
:
The Geospatial Delhi Limited (GSDL), a Govt. of NCT of Delhi Company formed in order to provide the geospatial information of National Capital Territory of Delhi (NCTD) to the Government of National Capital Territory of Delhi (GNCTD) and its organs such as DDA, MCD, DJB, State Election Department, DMRC etc., for the benefit of all citizens of Government of National Capital Territory of Delhi (GNCTD).

This paper describes the development of Geospatial Map based Election portal (GMEP) of NCT of Delhi. The portal has been developed as a map based spatial decision support system (SDSS) for pertain to planning and management of Department of Chief Electoral Officer, and as an election related information searching tools (Polling Station, Assembly and parliamentary constituency etc.,) for the citizens of NCTD. The GMEP is based on Client-Server architecture model. It has been developed using ArcGIS Server 10.0 with J2EE front-end on Microsoft Windows environment. The GMEP is scalable to enterprise SDSS with enterprise Geo Database \& Virtual Private Network (VPN) connectivity.

Spatial data to GMEP includes delimited precinct area boundaries of Voters Area of Polling stations, Assembly Constituency, Parliamentary Constituency, Election District, Landmark locations of Polling Stations \& basic amenities (Police Stations, Hospitals, Schools and Fire Stations etc.). GMEP could help achieve not only the desired transparency and easiness in planning process but also facilitates through efficient \& effective tools for management of elections. It enables a faster response to the changing ground realities in the development planning, owing to its in-built scientific approach and open-ended design.
\end{abstract}




\section{Introduction}

India is a constitutional democracy with a parliamentary system of government, and at the heart of the system is a commitment to hold regular, free and fair elections. These elections determine the composition of the government, the membership of the two houses of parliament, the state and union territory legislative assemblies, and the Presidency and vice-presidency. Elections are conducted according to the constitutional provisions, supplemented by laws made by Parliament. The Election Commission has the residuary powers under the Constitution to act in an appropriate manner. The Chief Electoral Officer department, Delhi is conducts the assembly and parliamentary election in Delhi.

Elections in India are events involving political mobilisation and organisational complexity on an amazing scale. The election processes are divided in three stages, Pre Election, During Election and Post Election. And the systematic conduction of election is the event management.

The NCT of Delhi is divided into 70 Assembly Constituency and 7 Parliamentary Constituency. The 11763 polling stations are allocated for smooth functioning of assembly election 2013 in Delhi. The Geographical Information System (G.I.S.) could play a vital role for systematic, smooth and transparent functioning of elections. GIS could facilitate in election management with thematic map representation as well as map based web application by using the spatial \& non spatial data.

\subsection{Problem at Hand}

The creation, updation and general management of electoral data (Boundaries of Polling Station's wise voter area) in terms of spatial and non-spatial data is a herculean task. The voluminous nature of data involved for proper record keeping is indeed cumbersome and cannot effectively be handled by traditional system of record keeping. The analogue system means acceptance of inflexibility resulting from data storage in fixed forms and formats. The system becomes less useful for many purposes and is rarely updated because of costs implication. The maps are easily displaced or destroyed because different people at different locations use them. An alternative approach taking into the account of limitations faced by the traditional system is of maintaining a coherent database in a scientific and efficient manner by use of advanced information technology is therefore, required. Hence, there will be improvements in planning, implementation and operation of the election department through provision of timely, reliable, sufficiently and accurately detailed data which will facilitate its decision making activities.

This paper describes the development of Geospatial Map based Election portal (GMEP) of NCT of Delhi. The portal has been developed as a map based spatial decision support system (SDSS) for pertain to planning and management of Department of Chief Electoral Officer, and as an election related information searching tools (Polling Station, Assembly and parliamentary constituency etc.,) for the citizens of NCTD. It enables a faster response to the changing ground realities in the development planning, owing to its in-built scientific approach and open-ended design. The GMEP is based on Client-Server architecture model. It has been developed using ArcGIS Server 10.0 with J2EE front-end on Microsoft Windows environment. The GMEP is scalable to enterprise SDSS with enterprise Geo Database \& Virtual Private Network (VPN) connectivity.

\section{Study Area}

28.61o N, 77.23o E is the geographical location of NCT of Delhi. NCT of Delhi is divided into nine (9) Election District. Total 70 Assembly Constituencies and 7 Parliamentary Constituencies are in NCT of Delhi.

\subsection{Spatial Data Dictionary}

Geospatial Delhi Limited (GSDL), a Govt. of NCT of Delhi Company, is a Geo-Knowledge enterprise, initially formulated as a Special Purpose Vehicle (SPV) to facilitate the Delhi State Spatial Data Infrastructure (DSSDI) Project. Each and every building and other spatial features (Like Buildings, Roads, Parks, Natural features etc) of NCT of Delhi has been captured in DSSDI project. The property data base was collected through field survey supplemented with concerned departmental inputs. This huge data is updating continuously by GSDL day by day. By using this data as a base layer and Electoral data (non spatial data) of Delhi Election department GSDL has created the electoral spatial layers (Election Boundary Layers- Assembly Constituency Boundary, Assembly Constituency Boundary, Election District Boundary, Section wise Polling Stations Voter Area boundary, Election point Layers- CEO Office, DEO Offices, SDM Election Offices, ERO \& AERO Offices, Voter Centres, and Counting Centres). These features represent the essential components of spatial database over which all secondary spatial as well as non-spatial information are superimposed for query/analysis and generation of thematic maps.

\subsection{Spatial Data Dictionary}

As per the methodology and guidelines described above, stateof-the-art ArcGIS Server 10.0 has been used for creation of the required spatial database in digital form. The digitized map information is stored in the GIS database appropriately in the form of layers, each layer representing a unique entity in the spatial data dictionary.

\section{GIS Platform}

ESRI ArcGIS Server 10.0 provides a standard framework for developing GIS applications. ArcGIS Server is both robust and extensible and its rich functionality allows developers to concentrate on solving organizational problems, not building GIS functionality from scratch. ArcGIS Server is based on Object oriented Framework. ArcGIS Server Objects support for simple map dialog boxes, multithreaded servers, and complex Windows desktop applications.

\subsection{Key features of ArcGIS Server}


Cost-effective deployment: ArcGIS Server Runtime is licensed per computer. This allows multiple ArcGIS applications to run on the same computer, incurring the cost of only a single runtime license.

Developer controls: ArcGIS Server provides a common set of developer controls that allow developers to easily deploy wellcrafted applications with a common look and feel. A common user experience leads to a short learning curve for users, so returns on the applications are quickly realized.

Cross platform functionality: ArcGIS Server application and all of its associated objects and controls are available on a wide variety of platforms including Windows, Linux. There is no need to change or add operating environments to the present computing infrastructure.

Dynamic display: It provides a mechanism for synchronized refreshing that allows moving objects, such as maps and graphics, to be displayed with fast refresh-rate technology.

Toolbars provide GIS tools, such as Pan, Zoom, Identify, Selection, and Editing, to interact with maps.

Developer tools: in ArcGIS Server include code projects, wizards, templates, and code snippets that integrate with your integrated development environment (IDE) to help you create custom desktop GIS applications.

\subsection{Application Architecture}

The architecture has been considered for the implementation of Geospatial Map based Election portal (GMEP) is scalable to enterprise DSS with enterprise Geodatabase \& VPN connectivity as shown in Fig. 1. Authenticate user access control is ensured by VPN \& database security by using enterprise Geo-database.

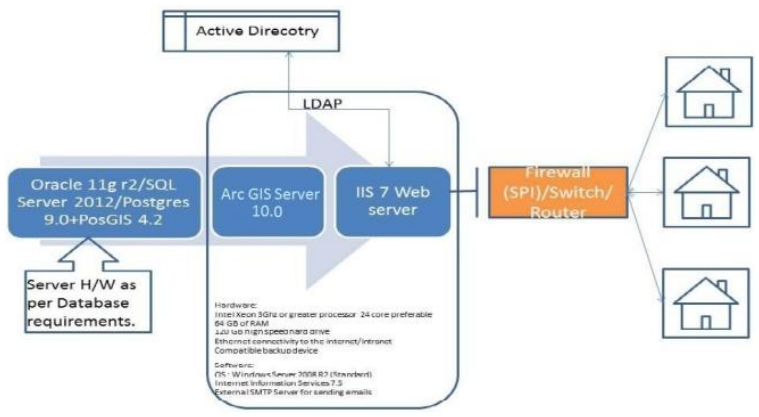

Figure 1 Enterprise Architecture

\subsection{Development Environment}

Arc Objects classes library is used in Server SDK environment using J2EE as front-end.

\section{Deployment Environment}

\subsection{Installation of ArcGIS Server Runtime}

ArcGIS Server software-based applications require that ArcGIS Server Runtime be installed on the end user's machine. Installation of the runtime can be handled in either of two ways:
1. End user runs the ArcGIS Server Runtime setup directly from the CD.

2. ArcGIS Server Runtime setup can be included within our own application's installation program.

\subsection{Authorization of the ArcGIS Server Runtime}

The mechanism used to license the ArcGIS Server Developer Kit on a per-machine, singleuse basis via an ESRI Copy Protection (*.ecp) file.

\subsection{Application Deployment}

After arranging Shape files layers in the proper sequence the map would be deploy in web platform by using ArcGIS web application platform.

\section{Geospatial Map based Election portal (GMEP) Features}

The following features of Geospatial Map based Election portal (GMEP)

1. Know your Assembly Constituency

2. Know your Parliamentary Constituency

3. Know your AERO, BLO

4. Know your Polling Station

5. Find your Location

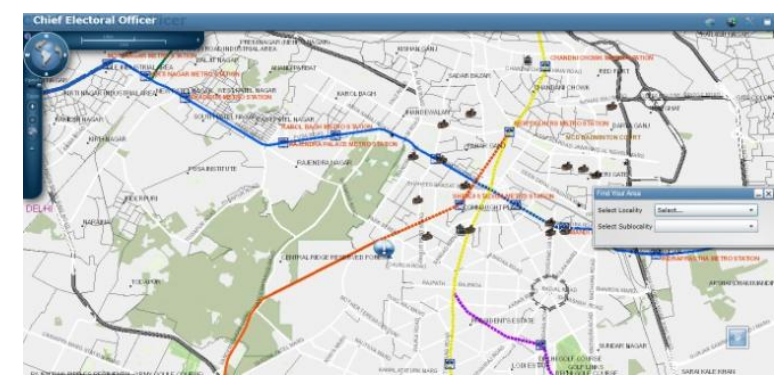

Figure 2 GMEP Front Page

\section{Salient Features}

The following are some of the salient features of Geospatial Map based Election portal (GMEP).

\section{Access control}

User can control the layers access

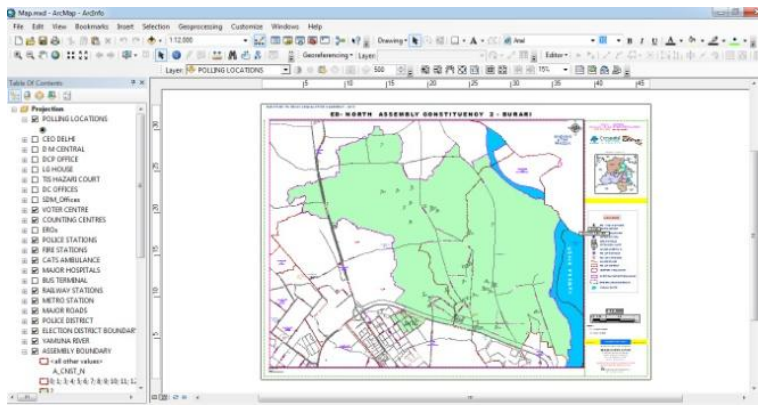


Figure 3 Layers Access Control

\section{Thematic Maps}

Thematic maps are often required to provide decision support information for spatial planning in several key areas. GMEP facilitates efficient generation and display of sector-wise thematic maps directly by the end user to enable him perform situation analysis and gain an insight for proper decisionmaking. It also supports map tool bar (zoom, pan) on any thematic map. It also provides map composition features.

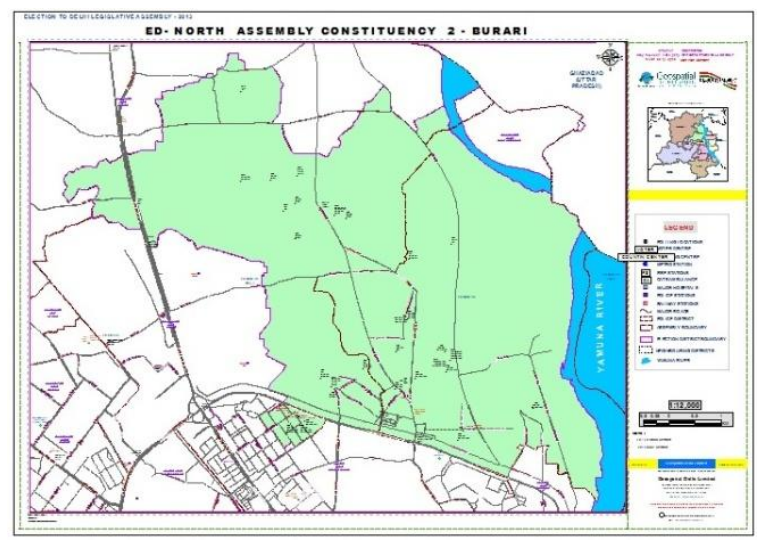

Figure 4 Assembly Constituency Map

\section{Query Shell}

An in-built query shell is also provided in GMEP to enable the end users build both simple and complex queries using any of the parameters (alone or in combination) contained in the attribute databases. The query shell thus aids in meaningful presentation of the data to arrive at appropriate planning decisions. Fig 5. Shows query shell template.

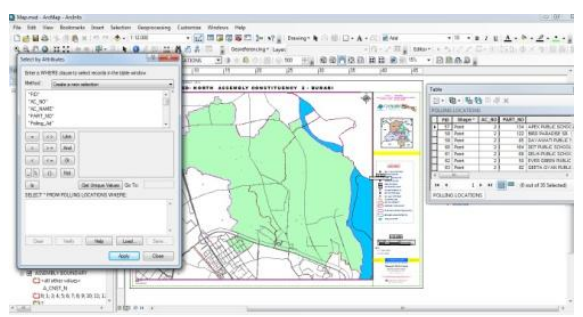

Figure 5 Query Shell

\section{Conclusion}

Spatial and attribute data of electoral data of NCT of Delhi. Which are presently acquired, processed, managed, stored and presented in analog form, can be digitalized. Digital system provides timely, accurate, and easier way of acquiring information, which is very vital in taking prompt and accurate decisions. GMEP is a Geomatics-based decision support system for planning \& management of Elections developed by GSDL, NCT of Delhi, India for Department of CEO, Delhi using ESRI ArcGIS Server. It is concluded that SDSS can be built using ArcGIS Server in a cost-effective manner.

\section{Acknoledgement}

The authors are thankful to Sh. Vijay Dev, Chief Electoral Officer, NCT of Delhi for his constant support and encouragement

\section{References}

1. Building Enterprise DSS Using ARCGIS Engine Geoamphere: A CASE STUDY, Vivek Chitale, M. Vinayak Rao, Geetanjali Mehta, Dhrubjyoti Sarma, N. Dhanasekar

2. White paper on Arc Engine 9.2 development (http://resources.esri.com/arcgisengine) 